\title{
Endoscopic submucosal dissection for early esophageal cancer in elderly patients with relative indications for endoscopic treatment
}

\author{
Authors \\ Ping-Hong Zhou ${ }^{1,2}$ \\ Institutions \\ 1 Endoscopy Center, Zhongshan Hospital of Fudan \\ University, Shanghai, China \\ 2 Endoscopy Research Institute of Fudan University, \\ Shanghai, China
}

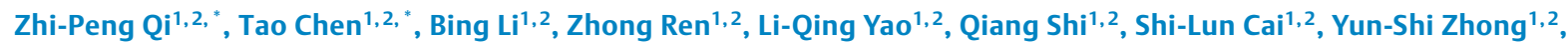

submitted 9.7.2017

accepted after revision 30.1 .2018

Bibliography

DOI https://doi.org/10.1055/a-0577-2560

Published online: 16.3.2018 | Endoscopy 2018; 50: 839-845

(c) Georg Thieme Verlag KG Stuttgart · New York

ISSN 0013-726X

Corresponding author

Ping-Hong Zhou, MD, PhD, , Endoscopy Center, Zhongshan

Hospital of Fudan University, 180 Fenglin Road, Shanghai

200032, China

Fax: +86-21-64041990

zhou.pinghong@zs-hospital.sh.cn

Supplementary Table e 3

Online content viewable at:

https://doi.org/10.1055/a-0577-2560

\section{ABSTRACT}

Background According to the Japanese Esophageal Society (JES) guidelines, early esophageal squamous cell carcinoma (SCC) involving the muscularis mucosae (M3) or upper submucosal (SM1) layers are relative indications for endoscopic submucosal dissection (ESD). Additional esophagectomy or chemoradiotherapy is recommended for patients with relative indications after evaluation. However, elderly patients ( $\geq 60$ years) with relative indications in China often refuse additional treatment because of the debilitating side effects. The aim of this study was to evaluate the long-term outcomes of elderly patients with relative indications who did not undergo additional treatment after ESD.

Methods Data from elderly patients with relative indications who underwent ESD for early esophageal SCC between January 2008 and December 2013 were reviewed retrospectively. Stricture and recurrence, and 5-year progression-free survival (PFS) and overall survival rates were compared with patients with absolute indications for ESD.

Results 158 elderly patients were included and analyzed (89 in the absolute indications group and 69 in the relative indications group). The baseline characteristics were balanced between the two groups. During 56 months (range 1-108) of follow-up, the postoperative stricture rates were similar in the absolute and relative indications groups $(21.3 \%$ vs. $31.9 \% ; P=0.13)$. The hazard ratio $(H R)$ for PFS in the absolute vs. the relative indications groups was 1.025 (95\% confidence interval $[\mathrm{Cl}] 0.36-2.95 ; P=$ $0.96)$. The 5 -year PFS rates were $90.5 \%(95 \% \mathrm{Cl} 83.44-$ $97.56)$ and $90.8 \%(95 \% \mathrm{Cl} 83.74-97.86)$ for the absolute and relative indications groups, respectively. The HR for overall survival in the absolute vs. the relative indications groups was $0.564(95 \% \mathrm{Cl} 0.13-2.52 ; P=0.45)$. The 5 -year overall survival rates were $96.6 \%(95 \% \mathrm{Cl} 92.88-100)$ and $95.6 \%(95 \% \mathrm{Cl} 90.70-100)$ for the absolute and relative indications groups, respectively.

Conclusions Based on this study, regular follow-up without additional treatment may be considered as another choice for elderly patients with early esophageal SCC and relative indications after ESD.

\section{Introduction}

During the few past decades, there has been a significant increase in the global incidence of esophageal cancer. In China, esophageal cancer is the third most common cancer and the

\footnotetext{
* These authors contributed equally to this paper.
}

fourth most fatal cancer [1]. Considering the mortality and morbidity associated with esophagectomy [2,3], endoscopic submucosal dissection (ESD) is becoming the preferred treatment for early esophageal squamous cell carcinoma (SCC), including high grade dysplasia and superficial esophageal cancer $[4,5]$. 
According to the Japanese Esophageal Society (JES) guideline, the absolute indication for esophageal ESD is intramucosal cancers involving the epithelium and lamina propria mucosae, whereas the relative indications for ESD encompass cancers that involve the muscularis mucosa or $<200 \mu \mathrm{m}$ invasion of the submucosa. In addition, when the risk of lymph node involvement is present, additional esophagectomy or chemoradiotherapy is more likely to be recommended for patients with relative indications, following clinical and histopathological evaluation [6].

The European Society of Gastrointestinal Endoscopy (ESGE) guideline also indicates that further therapy after ESD should be balanced against the risk of lymph node metastasis by a multidisciplinary discussion for lesions involving the muscularis mucosa or $<200 \mu \mathrm{m}$ invasion of the submucosa without lymphovascular invasion [7].

However, in China, many tumors with relative indications are found in elderly patients [8], a population that has a higher rate of comorbidities than younger individuals [9]. For this reason, additional treatment options are also somewhat limited for these patients.

No studies have been conducted to investigate the prognosis of elderly patients ( $\geq 60$ years) with relative indications who do not undergo additional treatment after ESD. The aim of this study was to evaluate the long term outcomes for these patients. This information could be useful in providing a reliable basis for ESD indications and supportive information for the decision about whether to utilize postoperative adjuvant therapy.

\section{Methods}

\section{Patients}

We studied elderly patients ( $\geq 60$ years) with early esophageal SCC who were treated at one center (Zhongshan Hospital of Fudan University) between January 2008 and December 2013. All of the tumors were evaluated using endoscopic ultrasonography and computed tomography (CT) prior to ESD in order to determine the depth of the lesion and metastasis.

The inclusion criteria were: 1 ) age $\geq 60$ years; 2 ) a postoperative pathological diagnosis of high grade intraepithelial neoplasia (HGIN) or SCC; and 3) submucosal involvement of no more than a depth of $200 \mu \mathrm{m}$ (SM1) on postoperative pathology.

The exclusion criteria were: 1 ) age < 60 years; 2 ) a pathological diagnosis other than HGIN or SCC (e.g. adenocarcinoma); 3 ) more advanced cancer on staging (SM2 or deeper [ $>200$ $\mu \mathrm{m}])$; 4) esophagectomy performed immediately, owing to an inability to perform ESD for the primary lesion; 5) additional surgical resection and/or chemoradiotherapy after ESD; 6) presence of esophagogastric junction lesions; and 7) incomplete follow-up.

The study was approved by the Ethics Committee at Zhongshan Hospital, in accordance with the Declaration of Helsinki. Based on endoscopic findings and histopathological diagnoses according to JES guidelines [6], the cases were divided into absolute and relative indications groups ( $\triangleright$ Fig. 1 ).

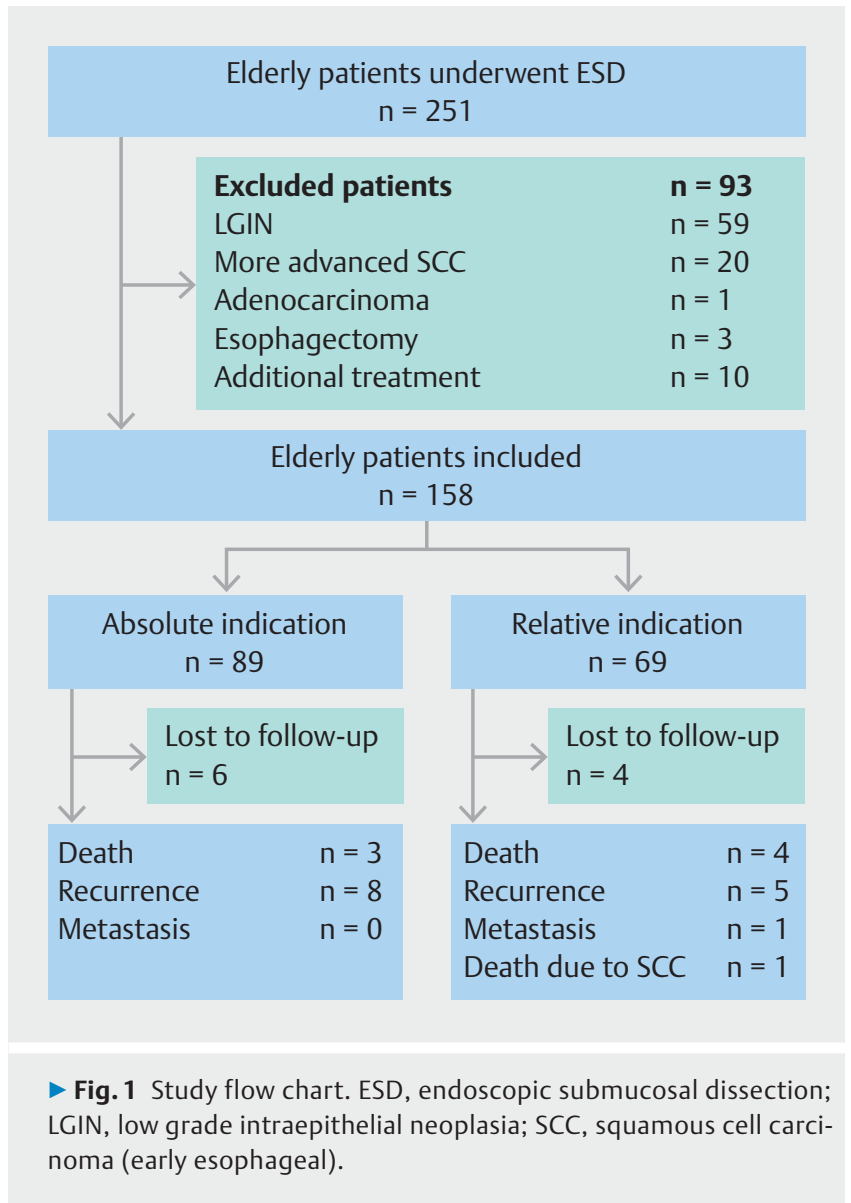

\section{ESD procedure and postoperative management}

All procedures were carried out under general anesthesia by experienced endoscopists via a standard method, as previously described [10] (> Fig.2). Antibiotics (second-generation cephalosporins, such as celaclor or cefuroxime), hemocoagulase injections (ethamsylate or P-aminomethylbenzoic acid), and omeprazole $(40 \mathrm{mg} /$ day) were routinely administered after the procedure. These medicines allowed oral intake to start on the third day, unless serious complications occurred. Patients usually remained in the hospital for $2-3$ days after ESD.

\section{Pathological examination}

Tissue specimens were fixed to a plastic foam plate using thin needles along their edges, and were then fixed in formalin. All samples were examined microscopically for histological type, depth of invasion, and lymphovascular invasion. Complete resection was defined as tissue free of tumor cells in both the basal and lateral margins. The histological criteria, classification, and assessment of the grade of differentiation corresponded to the World Health Organization classification [11].

\section{Data collection and follow-up}

Clinicopathological and endoscopic data, including patient, lesion, and clinical characteristics were collected and analyzed. Follow-up patient data were obtained from medical records. For patients who had moved away from our hospital, we at- 
tempted to obtain outcome details by telephone conversation with the patient or their family.

A postoperative stricture was defined as a stricture that required endoscopic treatment. A local recurrence was defined as an M1-SM1 lesion detected within $1 \mathrm{~cm}$ of the original lesion site within 6 months. Lymph node or distant metastasis was detected using CT or magnetic resonance imaging (MRI), and then verified via histological examination of the resected sample or biopsy. The start of the follow-up period was defined as the date of ESD, and the end of the follow-up period was defined as either the date of death or December 2016, whichever occurred first. Follow-up endoscopies, including conventional white-light endoscopy and narrow-band imaging were performed at 3, 6, and 12 months after the last endoscopic resection, and were subsequently followed up annually if no local recurrence was identified in two consecutive follow-up examinations. lodine staining and biopsy were performed when the previous resection site appeared suspicious for residual or recurrent lesions. Contrast-enhanced CT scan/MRI was recommended every 6-12 months to evaluate the presence of lymph node or distant metastasis.

\section{Statistical analysis}

Statistical analysis between groups was performed using the chi-squared test or Fisher's exact test and rank-sum test, as appropriate. Kaplan-Meier curves were constructed to analyze rates of survival, metastasis, and recurrence. The log-rank test was used to evaluate the significance of differences between curves.

SPSS software version 16.0 (SPSS Inc., Chicago, Illinois, USA) was used for statistical analysis, and $P<0.05$ was accepted to be statistically significant.

\section{Results}

\section{Patient characteristics}

In total, 158 patients were included in the study (119 men and 39 women). The median age was 66 years (range $60-84$ years). Based on the JES guidelines, patients were divided into two groups: the relative indications group $(n=69)$ and the absolute indications group $(n=89)$. There were no major imbalances between the two groups with regard to baseline characteristics ( $\triangleright$ Table 1). As of the last follow-up on December 2016, the overall median follow-up time was 56 months (range 1-108 months, interquartile range 47-68 months), with a missing follow-up rate of $6.3 \%(10 / 158)$. The missing follow-up rate in the absolute indications group was $6.7 \%$ (6/89) compared with $5.8 \%(4 / 69)$ in the relative indications group. There was no significant difference between the two groups $(P>0.99)$.

Esophageal stricture occurred in 41 patients (25.9\%) after ESD. All of these patients were treated by endoscopic balloon dilation for a mean of 5 times (range 1-14). Postoperative stricture occurred in $21.3 \%$ (19/89) of patients with absolute indications compared with $31.9 \%(22 / 69)$ of patients with relative indications $(P=0.13)$. The number of dilation procedures in the absolute and relative indications groups were 4 (range 1 11 ) and 5 (range $2-14$ ), respectively.
- Table 1 Baseline characteristics between the absolute and relative indications groups.

\begin{tabular}{|c|c|c|c|}
\hline Characteristics & $\begin{array}{l}\text { Absolute } \\
\text { indications }\end{array}$ & $\begin{array}{l}\text { Relative } \\
\text { indications }\end{array}$ & $P$ value \\
\hline Patients, n & 89 & 69 & \\
\hline $\begin{array}{l}\text { Age, median (range), } \\
\text { years }\end{array}$ & $64(60-79)$ & $67(60-84)$ & 0.09 \\
\hline Sex, male/female, n & $63 / 26$ & $56 / 13$ & 0.18 \\
\hline ASA grade, $n$ & & & 0.92 \\
\hline .1 & 26 & 20 & \\
\hline . II & 42 & 32 & \\
\hline - III & 21 & 17 & \\
\hline Lesions, $\mathbf{n}$ & 89 & 73 & \\
\hline Location & & & 0.09 \\
\hline - Upper third & 5 & 8 & \\
\hline - Middle third & 69 & 58 & \\
\hline - Lower third & 15 & 7 & \\
\hline $\begin{array}{l}\text { Tumor size, median } \\
\text { (range), mm }\end{array}$ & $28(4-90)$ & $26(6-47)$ & 0.46 \\
\hline
\end{tabular}

Circumferential

$>0.99$ range, $n$

\begin{tabular}{|l|r|r}
\hline$<3 / 4$ & 84 & 69 \\
\hline - $\geq 3 / 4$ & 5 & 4 \\
\hline
\end{tabular}

Pathological diagnosis, n

\begin{tabular}{|l|r|r|}
\hline - M1 (HGIN) & 77 & 0 \\
\hline - M2 & 12 & 0 \\
\hline - M3 & 0 & 62 \\
\hline - SM1 & 0 & 7 \\
\hline
\end{tabular}

Lymphovascular involvement, $\mathrm{n}$

\begin{tabular}{|r|r|r|}
\hline . Yes & 3 & 6 \\
\hline - No & 86 & 67 \\
\hline
\end{tabular}

\begin{tabular}{|l|l|l|}
\hline Complete resection & 0.44 \\
\hline
\end{tabular}

rate, $\mathrm{n}$

\begin{tabular}{|l|r|r}
\hline - Yes & 89 & 72 \\
\hline - No & 0 & 1 \\
\hline
\end{tabular}

ASA, American Society of Anesthesiologists; HGIN, high grade intraepithelial neoplasia.

\section{Prognosis outcomes}

Of the entire study population, 14 patients (8.9\%) experienced disease progression, defined as esophageal mucosal recurrence, and distant or lymph node metastasis. The postoperative esophageal mucosal recurrence rates for the absolute and relative indications groups were $9.0 \%(8 / 89)$ and $7.2 \%(5 / 69)$, 

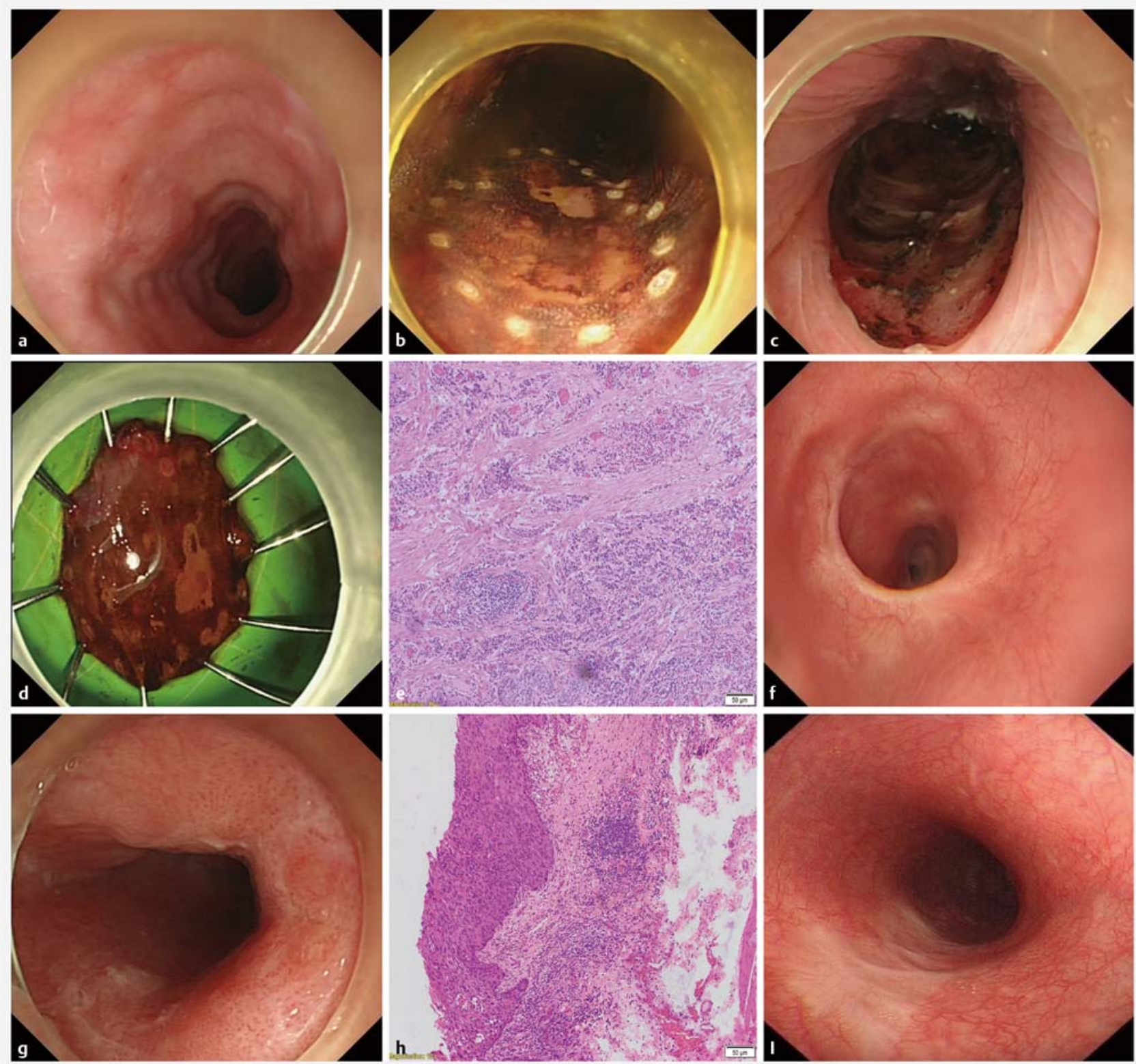

- Fig. 2 Endoscopic submucosal dissection (ESD) for an early esophageal squamous cell carcinoma (SCC). a On endoscopy, a flat erosive mucosa was seen in the esophagus $30-35 \mathrm{~cm}$ from the incisors. b lodine staining showed that the lesion was unstained and irregular. Lesion margins were marked. c A circular mucosal incision along marking dots was made after submucosal injection; the image shows the resection site following ESD. $\mathbf{d}$ The resected specimen. e The pathology report of the specimen showed the lesion involving the muscularis mucosa. $\mathbf{f}$ The healing wound after 3 months showing a postoperative stricture; the stricture was treated by endoscopic balloon dilation. $\mathbf{g}$ A flat erosive lesion was found on gastroscopy in the esophagus $30-33 \mathrm{~cm}$ from the incisors. $\mathbf{h}$ After ESD, the pathology results showed high grade intraepithelial neoplastic lesions. i Small scar could be seen on the mucosa after 3 months.

respectively $(P=0.69)$. The median recurrence times in the absolute and relative indications groups were 28 and 24 months, respectively. Among the patients with recurrence, all were successfully re-treated with ESD. The metastasis rates for the absolute and relative indications groups were $0.0 \%(0 / 89)$ and $1.4 \%$ $(1 / 69)$, respectively $(P=0.44)$. In the first 12 months after ESD, liver and lymph node metastases were seen in one case from the relative indications group ( $\triangleright$ Table 2 ).
At the time of analysis, seven patients (4.4\%) died during the follow-up period, including three $(3.4 \%)$ in the absolute group and four $(5.8 \%)$ in the relative indications group $(P=0.73)$ ( $\vee$ Table 2). In the absolute indications group, one patient died from pneumonia within a month of ESD, and two patients died from other causes. In the relative indications group, one patient died from cachexia caused by postoperative stricture, one patient died from cancer metastasis, and two patients died from other cancers (pancreatic and bladder cancer, respectively). 
- Table 2 The adverse events and prognosis outcome in the absolute and relative indications groups.

\begin{tabular}{|c|c|c|c|}
\hline & $\begin{array}{l}\text { Absolute } \\
\text { indications } \\
n=89\end{array}$ & $\begin{array}{l}\text { Relative } \\
\text { indications } \\
n=69\end{array}$ & $P$ value \\
\hline \multicolumn{4}{|l|}{ Adverse events, n (\%) } \\
\hline $\begin{array}{l}\text { - Postoperative } \\
\text { stricture }\end{array}$ & $19(21.3)$ & $22(31.9)$ & 0.13 \\
\hline \multicolumn{4}{|l|}{ Prognosis, n (\%) } \\
\hline - Recurrence & $8(9.0)$ & $5(7.2)$ & 0.69 \\
\hline - Metastasis & $0(0)$ & $1(1.4)$ & 0.44 \\
\hline - Death & $3(3.4)$ & $4(5.8)$ & 0.73 \\
\hline $\begin{array}{l}\text { - Death due to early } \\
\text { esophageal SCC }\end{array}$ & $0(0)$ & $1(1.4)$ & 0.44 \\
\hline
\end{tabular}

The progression-free survival (PFS) Kaplan-Meier curves of the 158 patients are presented in $\mathbf{F i g}$. 3a. The hazard ratio (HR) for the absolute vs. relative indications groups was 1.025 (95\% confidence interval $[\mathrm{Cl}] 0.36-2.95 ; P=0.96$ ). The 5-year PFS rates were $90.5 \%(95 \% \mathrm{Cl} 83.44-97.56)$ for the absolute indications group and $90.8 \%(95 \% \mathrm{Cl} 83.74-97.86)$ for the relative indications group.

The Kaplan - Meier curves of overall survival are presented in - Fig. 3b. The HR for the absolute vs. relative indications group was $0.564(95 \% \mathrm{Cl} 0.13-2.52 ; P=0.45)$. The 5 -year overall sur- vival rates were $96.6 \%(95 \% \mathrm{Cl} 92.88-100)$ for the absolute indications group and $95.6 \%(95 \% \mathrm{Cl} 90.70-100)$ for the relative indications group.

\section{Discussion}

According to the JES and ESGE guidelines, additional treatment after ESD should be considered against the risk of lymph node metastasis for patients with relative indications. However, in China, a surprisingly large proportion of elderly patients ( $\geq 60$ years) with relative indications refuse additional treatment after ESD owing to higher rates of debilitating symptoms following additional treatment. The current study assessed the long term effectiveness of ESD for early esophageal SCC in elderly patients with relative indications.

Despite the fact that patients with relative indications are at risk of lymph node metastasis from lesions reaching the M3 or SM1 stage [12,13], high rates of 5-year PFS and 5-year overall survival were still achieved. These results were similar to outcomes in elderly patients with absolute indications. Furthermore, no patient died from cancer progression in this study.

The main reason elderly patients with relative indications refuse additional treatment after ESD is the high rate of adverse events resulting from esophagectomy and chemoradiotherapy. One study indicated that the incidence of postoperative adverse events in patients aged $70-79$ years was significantly higher ( $42 \%$ vs. $32 \%$; $P 0.05$ ), and the 5 -year survival rate was significantly worse $(29 \%$ vs. $38 \%$; $P<0.01)$, than in patients younger than 70 years [14]. Other studies have reached the same conclusion [15]. Despite the chemoradiotherapy-induced adverse events, such as hematological toxicities, radiation
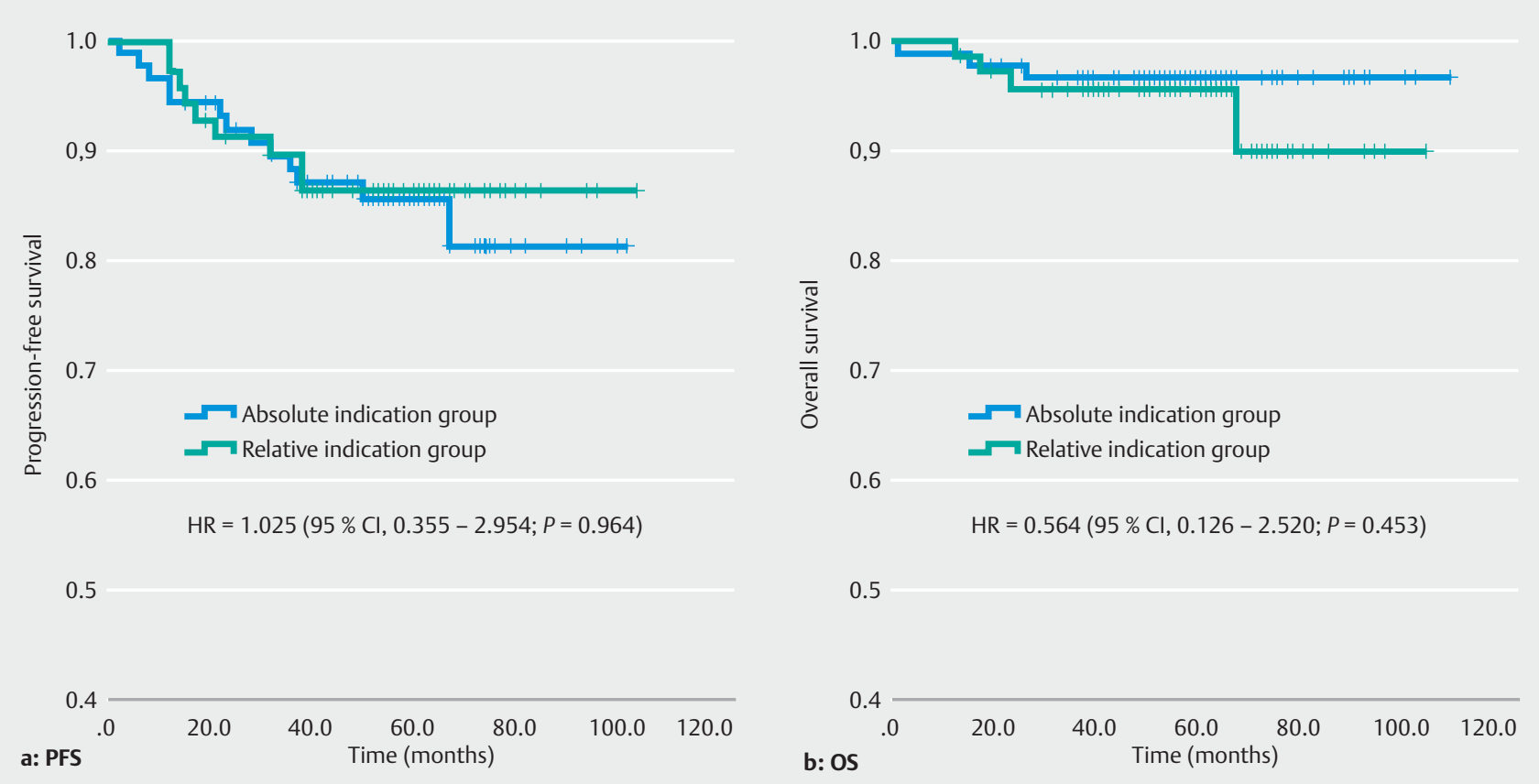

Fig. 3 The prognosis outcome in the absolute and relative indications groups. a Progression-free survival. b Overall survival. HR, hazard ratio; $\mathrm{Cl}$, confidence interval. 
pneumonia, and radiation esophagitis, which are less harmful than the esophagectomy-induced adverse events, the rate of these adverse events remains high for elderly patients [16]. These findings indicate that age is a main factor increasing the risk of adverse events, and that it plays an important role in decisions regarding treatment strategy, which must consider the risk of adverse events, for patients with relative indications.

Unlike the adverse events associated with additional treatment, the most challenging long term adverse event after ESD is stricture formation. It has severe effects upon the quality of life in patients and can even endanger their lives. In our study, the rate of stricture formation was higher than that reported in previous studies $[10,17,18]$, and one patient in the relative indications group died from cachexia caused by stricture. This can be explained by submucosal fibrosis, likely owing to agerelated changes in the esophagus, such as dilation and tortuosity from a corkscrew esophagus [19]. Another possible reason is that in the past, steroid therapy was not commonly used following ESD. After much investigation, it has been firmly established that steroid therapy could prevent a post-ESD stricture [20 - 22]. Moreover, in our study, the stricture rate for the relative indications group (31.9\%) was higher than that for the absolute indications group (21.3\%), but the difference was not statistically significant. The higher rate of stricture in the relative indications group can be explained by the relatively deep invasion and dissection. In a previous study, lesions involving a depth greater than the $\mathrm{M} 2$ were verified as a reliable risk factor for post-ESD stricture $[10,23]$. Therefore, it is important that endoscopists to use steroids to prevent possible stricture formation.

In our study, all strictures were managed with endoscopic dilation rather than surgical treatment. Some patients required long term endoscopic treatment. However, previous studies have shown that stricture dilation carries a risk of esophageal perforation, and multiple dilations are a reliable risk factor for the development of perforation during dilation therapy following ESD [24]. Prevention of a post-ESD stricture is more meaningful than the ability to manage a stricture. Recently, oral steroid administration and local steroid injection have emerged as two successful approaches to the prevention of stricture [22, 25]. In our experience, local injection of triamcinolone during the ESD procedure and oral prednisone can effectively prevent stricture in elderly patients with relative indications and mucosal resection covering $3 / 4$ of the entire circumference, but this observation requires further verification.

ESD is associated with favorable results in terms of long term outcomes [26]. We verified these results in our study. However, endoscopic resection for early esophageal SCC has a relatively high recurrence rate, particularly in patients with relative indications, but most patients with recurrence can be re-treated endoscopically [27-29]. In our study, among the patients with recurrence, all were successfully re-treated with ESD. Therefore, regular follow-up and re-treatment of recurrent lesions endoscopically is effective and may decrease or avoid additional esophagectomy for elderly patients with relative indications. Furthermore, early esophageal SCC has the potential for lymph node metastasis, especially for tumors invading the M3; the lymph node metastasis rate ranges from $0 \%$ to $25 \%$ in different studies $[13,30,31]$. However, there was a low incidence of lymph node and distant metastasis in the relative indications group in the current study. This result may be due to our study groups, which had a low rate of lymphovascular involvement. Moreover, a recent large scale study analysis of surveillance and end results of $\mathrm{T} 1$ lesions showed that there were no significant relationships between the lymph node metastasis of $\mathrm{T} 1$ lesions and the early esophageal SCC survival rate [31]. Therefore, considering the high rates of debilitating symptoms and chemoradiotherapy-induced adverse events, and the weak relationship between lymph node metastasis and survival, it may not be necessary for elderly patients with relative indications to undergo chemoradiotherapy.

This study has some limitations. It did not compare the long term outcomes of patients with relative indications who did not undergo additional treatment after ESD with patients who did receive additional treatment, because the number of patients undergoing additional treatment was limited (see $>$ Supplementary Table e3, available online). The other limitation of this study is its retrospective and single-center design. A prospective multicenter study with a large patient cohort is warranted.

\section{Conclusion}

Based on our study, elderly patients with early esophageal SCC and relative indications who did not undergo additional treatment after ESD showed comparable outcomes to patients with absolute indications. Therefore, regular follow-up without any additional treatment may be considered as another choice for elderly patients with early esophageal SCC and relative indications after ESD.

\section{Competing interests}

None.

References

[1] Chen W, Zheng R, Baade PD et al. Cancer statistics in China, 2015. CA Cancer J Clin 2016; 66: 115-132

[2] Briez N, Piessen G, Bonnetain F et al. Open versus laparoscopicallyassisted oesophagectomy for cancer: a multicentre randomised controlled phase III trial - the MIRO trial. BMC Cancer 2011; 11: 310

[3] Allum WH, Bonavina L, Cassivi SD et al. Surgical treatments for esophageal cancers. Ann N Y Acad Sci 2014; 1325: $242-268$

[4] Luo LN, He L], Gao XY et al. Evaluation of preoperative staging for esophageal squamous cell carcinoma. World J Gastroenterol 2016; 22: $6683-6689$

[5] Mannath J, Ragunath K. Role of endoscopy in early oesophageal cancer. Nat Rev Gastroenterol Hepatol 2016; 13: $720-730$

[6] Kuwano H, Nishimura Y, Oyama T et al. Guidelines for diagnosis and treatment of carcinoma of the esophagus April 2012 edited by the Japan Esophageal Society. Esophagus 2015; 12: 1-30

[7] Pimentel-Nunes P, Dinis-Ribeiro M, Ponchon T et al. Endoscopic submucosal dissection: European Society of Gastrointestinal Endoscopy (ESGE) guideline. Endoscopy 2015; 47: 829-854 
[8] Jiang D, Li X, Wang $\mathrm{H}$ et al. A retrospective study of endoscopic resection for 368 patients with early esophageal squamous cell carcinoma or precancerous lesions. Surg Endosc 2017; 31: 2122 - 2130

[9] Jing W, Guo H, Kong L et al. Clinical outcomes of elderly patients (70 years) with resectable esophageal squamous cell carcinoma who underwent esophagectomy or chemoradiotherapy: a retrospective analysis from a single cancer institute. Medicine (Baltimore) 2016; 95: e5630

[10] Shi Q, Ju H, Yao LQ et al. Risk factors for postoperative stricture after endoscopic submucosal dissection for superficial esophageal carcinoma. Endoscopy 2014; 46: 640-644

[11] Li ZS, Li Q. [The latest 2010 WHO classification of tumors of digestive system]. Zhonghua Bing Li Xue Za Zhi 2011; 40: 351 - 354

[12] Bollschweiler E, Baldus SE, Schroder W et al. High rate of lymph-node metastasis in submucosal esophageal squamous-cell carcinomas and adenocarcinomas. Endoscopy 2006; 38: 149-156

[13] Eguchi T, Nakanishi Y, Shimoda T et al. Histopathological criteria for additional treatment after endoscopic mucosal resection for esophageal cancer: analysis of 464 surgically resected cases. Mod Pathol 2006; 19: $475-480$

[14] Morita M, Egashira A, Yoshida R et al. Esophagectomy in patients 80 years of age and older with carcinoma of the thoracic esophagus. J Gastroenterol 2008; 43: 345-351

[15] Cijs TM, Verhoef C, Steyerberg EW et al. Outcome of esophagectomy for cancer in elderly patients. Ann Thorac Surg 2010; 90: 900 - 907

[16] Jing W, Zhu H, Guo H et al. Feasibility of elective nodal irradiation (ENI) and involved field irradiation (IFI) in radiotherapy for the elderly patients (aged $\geq 70$ years) with esophageal squamous cell cancer: a retrospective analysis from a single institute. PLoS One 2015; 10: e143007

[17] Libanio D, Pimentel-Nunes P, Dinis-Ribeiro M. Complications of endoscopic resection techniques for upper $\mathrm{Gl}$ tract lesions. Best Pract Res Clin Gastroenterol 2016; 30: 735 - 748

[18] Song BG, Min YW, Lee JH et al. Efficacy and safety of endoscopic submucosal dissection in elderly patients with esophageal squamous cell carcinoma. Surg Endosc 2017; 31: 3905-3911

[19] DeVault KR. Presbyesophagus: a reappraisal. Curr Gastroenterol Rep 2002; 4: $193-199$

[20] Sato H, Inoue H, Kobayashi Y et al. Control of severe strictures after circumferential endoscopic submucosal dissection for esophageal carcinoma: oral steroid therapy with balloon dilation or balloon dilation alone. Gastrointest Endosc 2013; 78: 250 - 257

[21] Ratone JP, Bories E, Caillol F et al. Oral steroid prophylaxis is effective in preventing esophageal strictures after large endoscopic resection. Ann Gastroenterol 2017; 30: 62 -66

[22] Kadota T, Yano T, Kato T et al. Prophylactic steroid administration for strictures after endoscopic resection of large superficial esophageal squamous cell carcinoma. Endosc Int Open 2016; 4: E1267-E1274

[23] Ono S, Fujishiro M, Niimi K et al. Predictors of postoperative stricture after esophageal endoscopic submucosal dissection for superficial squamous cell neoplasms. Endoscopy 2009; 41: 661-665

[24] Takahashi H, Arimura Y, Okahara S et al. Risk of perforation during dilation for esophageal strictures after endoscopic resection in patients with early squamous cell carcinoma. Endoscopy 2011; 43: $184-189$

[25] Hanaoka N, Ishihara R, Takeuchi Y et al. Intralesional steroid injection to prevent stricture after endoscopic submucosal dissection for esophageal cancer: a controlled prospective study. Endoscopy 2012; 44: $1007-1011$

[26] Jin XF, Gai W, Chai TH et al. Comparison of endoscopic resection and minimally invasive esophagectomy in patients with early esophageal cancer. J Clin Gastroenterol 2017; 51: 223-227

[27] Tsujii Y, Nishida T, Nishiyama O et al. Clinical outcomes of endoscopic submucosal dissection for superficial esophageal neoplasms: a multicenter retrospective cohort study. Endoscopy 2015; 47: 775 - 783

[28] Nakagawa K, Koike T, lijima K et al. Comparison of the long-term outcomes of endoscopic resection for superficial squamous cell carcinoma and adenocarcinoma of the esophagus in Japan. Am J Gastroenterol 2014; 109: 348-356

[29] Yamashina T, Ishihara R, Nagai K et al. Long-term outcome and metastatic risk after endoscopic resection of superficial esophageal squamous cell carcinoma. Am J Gastroenterol 2013; 108: 544 - 551

[30] Araki K, Ohno S, Egashira A et al. Pathologic features of superficial esophageal squamous cell carcinoma with lymph node and distal metastasis. Cancer 2002; 94: 570-575

[31] Dubecz A, Kern M, Solymosi N et al. Predictors of lymph node metastasis in surgically resected T1 esophageal cancer. Ann Thorac Surg 2015; 99: 1879-1886 